\title{
Estrategias ambientales, legitimación gubernamental y regulación social: exploraciones en cuatro ciudades colombianas
}

\author{
Peter Charles BRAND*
}

\begin{abstract}
This paper explores the political meaning of environmental urban management. It argues that the environment only becomes important as values are added to it, making possible its extraction from the realm of the natural sciences, and attach a social meaning to it. In the urban field, this potential meaning lays on the urban administrations, and it is achieved through discursive constructions and spatial representations framed by a "project of the city", or by the way in which each city "talks about itself". In the cities of the neoliberal globalisation, the environment acquires a special importance in order to build meanings of collective welfare and thus legitimise the local governments, as well as regulate social behaviour. However, the way in which this is done depends on urban trajectories, political traditions, institutional capacity and regional cultures. These processes are investigated in the four most important cities in Colombia: Bogota, Medellin, Cali and Barranquilla.
\end{abstract}

Keywords: urban environment, discourse, legitimisation, regulation, Colombia.

\section{Resumen}

En este artículo se explora el significado político de la gestión ambiental urbana. Se argumenta que el ambiente únicamente se vuelve importante en la medida que en él se construyan valores que lo extraigan de las ciencias naturales para dotarlo de sentido social. En el ámbito urbano, esta potencia significacional se ubica en las administraciones urbanas, y se realiza mediante construcciones discursivas y representaciones espaciales enmarcadas en un 'proyecto de ciudad', o la manera en que cada ciudad 'habla de sí misma'. En las ciudades de la globalización neoliberal, el ambiente adquiere especial importancia para construir sentidos de bienestar colectivo y así legitimar a los gobiernos locales y regular el comportamiento social. Sin embargo, cómo lo hace depende de las trayectorias urbanas, las tradiciones políticas, la capacidad institucional y las culturas regionales. Estos procesos se indagan en las cuatro ciudades principales de Colombia: Bogotá, Medellín, Cali y Barranquilla.

Palabras clave: ambiente urbano, discurso, legitimación, regulación, Colombia. edu.co.

*Universidad Nacional de Colombia (sede Medellín). Correo-e: pbrand@unalmed. 


\section{Introducción ${ }^{1}$}

El cambio del siglo presenció una notable preocupación por el ambiente urbano. Desde la Cumbre Mundial de Río de Janeiro de 1992, el tema del desarrollo sostenible giró hacia la acción concreta a escala local (Agendas 21 Locales) y las ciudades empezaron a entenderse como piezas clave para remediar el deterioro ambiental global. Además, en contraste con los reticentes gobiernos nacionales, los problemas ambientales fueron asumidos con entusiasmo por muchas administraciones locales. En el ámbito urbano, la política ambiental internacional resonaba con crecientes dificultades con la prestación de 'servicios ambientales' como el agua y los paisajes; la contaminación del aire y el suelo se volvió un asunto sensible en cuanto a la salud humana, y una imagen urbana 'verde y limpia' se erigió como un requisito indispensable en el nuevo entorno de la competitividad económica. Si bien en Colombia, como en muchos países, se estableció un amplio sistema de instituciones, programas, mecanismos de financiación, normas y sanciones para la protección de los recursos naturales en función del desarrollo sostenible a escala nacional, ${ }^{2}$ en cada ciudad se armó un paquete propio de instrumentos para gestionar los problemas locales.

En este artículo se pretende explorar el significado político de la gestión ambiental urbana y su impacto social y espacial en las ciudades. Frente a la creciente tecnificación del tema ambiental, por un lado, y en medio de las deterioradas condiciones socia-

${ }^{1}$ Una versión más amplia de esta ponencia se encuentra en Peter Brand y Fernando Prada, La invención de futuros urbanos: estrategias de competitividad económica y sostenibilidad ambiental en las cuatro ciudades principales de Colombia, Tercer Mundo-Universidad Nacional de Colombia, Bogotá, 2003.

${ }^{2}$ El Ministerio del Medio Ambiente se instituyó en 1993, poco después de la Cumbre de Río de Janeiro. El ministerio es la cúspide de un sistema jerárquico conformado por cinco instituciones nacionales de investigación, más de 30 corporaciones autónomas regionales como 'autoridades ambientales' (con la función de ejecutar la política nacional a partir de poderes normativos y recursos financieros propios), y las entidades territoriales (departamentos y municipios), que tienen responsabilidades ambientales específicas. El sistema en general está abierto e integra al sector privado, las universidades, las ONG, las comunidades, etc. Las ciudades con más de un millón de habitantes pudieron asumir la autoridad ambiental en el área urbana de sus jurisdicciones. Así se establecieron el Departamento Administrativo del Medio Ambiente, DAMA, en la ciudad de Bogotá; el Departamento Administrativo de Gestión del Medio Ambiente, DAGMA, en Cali; y el Departamento Administrativo Distrital del Medio Ambiente, DADIMA, en Barranquilla; en Medellín esta función fue asumida por la ya existente figura administrativa del Área Metropolitana del Valle de Aburrá. Los alcaldes nombran a los directores de dichas instituciones, lo que abre importantes espacios para la articulación de las políticas ambientales al desarrollo urbano integral. 
les, por otro, se indaga la manera en que la gestión ambiental pudiera adquirir la vitalidad e importancia que tiene en las ciudades colombianas. En particular, interesa la articulación de la gestión ambiental con los intereses de los gobiernos locales. Más allá de la racionalidad científica derivada de la ecología, se argumenta que el ambiente únicamente se vuelve importante en tanto se construyen ahí valores que lo extraen del reino de las ciencias naturales para dotarlo de sentido social. Se propone que este traslado del ambiente a un campo de acción socialmente significativo es una competencia de las administraciones urbanas, que se realiza con base en construcciones discursivas y representaciones espaciales enmarcadas en un 'proyecto de ciudad'.

Este proyecto de ciudad del siglo XXI está enmarcado por los dilemas de la globalización neoliberal. La globalización ha traído consecuencias socialmente regresivas para las ciudades, los prometidos beneficios amplios no se han materializado y se han profundizado la desigualdad social y la pobreza. Al mismo tiempo, las reformas del Estado han quitado a los gobiernos locales los instrumentos institucionales y fiscales para garantizar un bienestar mínimo para las mayorías urbanas. Se indaga, entonces, hasta qué punto y cómo los gobiernos urbanos, para reestablecer un sentido de legitimidad, han construido en el ambiente una esfera de 'calidad de vida urbana' aparentemente desligada de la economía, al mismo tiempo generando un nuevo campo de regulación social y control de poblaciones urbanas cada vez más informalizadas.

El acercamiento al tema, en este artículo, privilegia el análisis del discurso, aunque desde luego las posibilidades no se agotan ahí. En esta exploración aplicada no cabe una exposición sistemática del método general del análisis de discurso, por lo demás una estrategia epistemológica compleja en sus estructuras conceptuales y con múltiples opciones temáticas y matices analíticos (Brand, 2005; Sharp y Richardson, 2001; Harré et al., 1999; Harvey, 1996; Fairclough, 1992). Basta observar que el análisis del discurso ha tenido una creciente utilización en los últimos años, tanto en los estudios urbano-regionales (Sandercock, 2003; Rydin, 2003; Huxley, 2002; Keil, 2002; Jessop, 1999) como en los estudios ambientales (Darrier, 1999; Acselrad, 1999; Lanthier y Olivier, 1999; Hajer, 1995). Especialmente para los ambientalistas, el interés en el discurso se debe en buena parte a la brecha que existe entre los planteamientos formales (discursivos) y la realidad (material), entre lo dicho y lo hecho concerniente al desarrollo sostenible. Pero más aún, el desarrollo soste- 
nible es sobre todo una construcción discursiva: la utilización de palabras para conformar un sentido particular del futuro. La sostenibilidad no existe como realidad objetiva y, por lo tanto, como señala Acselrad (1999: 36), no depende del análisis sistemático de lo real sino que más bien obedece a la lógica de las prácticas, articulándose "a los efectos sociales deseados, a las funciones prácticas que el discurso pretende volver realidad objetiva”.

El propósito entonces consiste en explorar los sentidos políticos construidos por medio del discurso ambiental; no el sentido 'en general' sino los sentidos particulares en situaciones concretas. Se trata de situaciones urbanas en las cuales el discurso sobre el ambiente se construye en relación con la ciudad en su conjunto, y con los problemas y desafíos (los momentos no discursivos) que enfrentan las administraciones locales, relacionados con las realidades económicas, sociales, políticas y urbanísticas. Con este acercamiento dialéctico al discurso como lenguaje en acción, se presenta la necesidad de abrir la mirada hacia la acción urbana más amplia: los procesos de urbanización y los fenómenos socioespaciales en general. En estos procesos, el discurso ambiental contribuye a dar sentido y orientar intervenciones, al establecer versiones dominantes de la verdad, desplegar el poder en el entendimiento de los problemas y el diseño de soluciones, privilegiar unos temas y marginar otros, etc., en la búsqueda permanente de 'efectos de verdad'.

Con el interés centrado en los efectos políticos, se analizan principalmente los programas de los gobiernos locales, los planes de desarrollo urbano y los programas institucionales de las entidades del Estado local, y en menor medida fragmentos de discurso tomados de entrevistas y de los medios de comunicación masiva. Se privilegia así la construcción discursiva, pero también son importantes el papel de las instituciones ambientales especializadas en la movilización del sentido mediante sus intervenciones espaciales y la extensa reglamentación del comportamiento ciudadano, asuntos que se comentan más someramente. Finalmente, por medio del estudio comparativo se busca comprender las características generales de este fenómeno en las principales ciudades de Colombia e identificar la importancia de otras variables como las trayectorias urbanas, las tradiciones políticas, la capacidad institucional y las culturas regionales en cuanto a la explotación política del ambiente en cada ciudad particular.

Las ciudades estudiadas son la capital y los tres centros regionales más importantes de Colombia. El bajo nivel de integración 
geográfica nacional incidió en la determinación de trayectorias urbanas muy diversas, con ritmos de crecimiento, economías, geografías físicas, culturas, élites sociales y dirigencias políticas fuertemente regionalizadas. Bogotá es la ciudad capital, con una población de aproximadamente siete millones de habitantes, y está ubicada en un altiplano andino a 2,600 metros sobre el nivel del mar en la cordillera oriental. Medellín, con casi dos millones de habitantes y centro de un área metropolitana con una población total de tres millones, está asentada en la escarpada cordillera central a 1,500 metros sobre el nivel del mar. Cali se sitúa en la amplia planicie del río Cauca, a 1,000 metros sobre el nivel del mar, y cuenta con una población ligeramente superior a los dos millones de habitantes y con una fuerte influencia de la cultura negra de la costa Pacífica. Barranquilla es una ciudad caribeña, localizada en la costa Atlántica y principal puerto de Colombia hasta la década de 1930, con una población de aproximadamente 1’300,000 habitantes.

\section{El desarrollo sostenible y la ciudad neoliberal}

La Cumbre Mundial sobre el Desarrollo Sostenible realizada en Johannesburgo en 2002 puso en clara evidencia las críticas al desarrollo sostenible que habían ido acumulándose durante la década anterior. No se trata solamente de la falta de progreso y la reticencia de la mayoría de los gobiernos del mundo para adquirir compromisos serios frente a los grandes problemas ecológicos globales, sino también de la manera en que el manejo del tema ambiental en general había sido asimilado y apropiado por los intereses del capital y sus agencias internacionales, como el Banco Mundial, el Fondo Monetario Internacional y la Organización Mundial del Comercio (Middleton y O'Keefe, 2003). De hecho, desde el Informe Brundtland de 1986, y pasando por la Declaración de Río de Janeiro en 1992, la política internacional del desarrollo sostenible ha estado profundamente comprometida con las premisas neoliberales: el libre comercio, las reformas del Estado, la privatización, las soluciones del mercado y las respuestas tecnológicas subyacen explícitamente a lo largo de sus articulados.

Como parte de la globalización neoliberal, la noción de sostenibilidad aporta, por lo menos formalmente, una visión a largo plazo, una dosis de ética y una invitación a participar, así como una demanda por (re)regular actividades y comportamientos para 
que se ajusten a la necesidad de conservación, protección y recuperación de los recursos naturales. En ningún caso ha tenido efectos significativos. Tal como se ha comentado ampliamente, el desarrollo sostenible ortodoxo es un pensamiento ambiental 'blando', en el sentido de confiar en ajustes marginales al desarrollo capitalista para minimizar los impactos ambientales. Esta ortodoxia, que no incorpora ninguna lógica ecológica ni hace concesiones culturales de importancia, ha sido descrita por Hajer (1995) en términos de la "modernización ecológica”, controlada por una alianza entre los grandes centros de poder empresarial, gubernamental y científico.

Frente a esta situación, la gran mayoría de los estudios sobre el ambiente se limitan estrechamente a los recursos naturales y ecosistémicos, como si tuvieran una autonomía absoluta derivada de las leyes de la naturaleza. No se tiene en cuenta que el entendimiento de la naturaleza como recurso natural, organizada en ecosistemas, sometida a leyes propias, merecedora de análisis técnicos y de administración, es una idea reciente; ni mucho menos que este entendimiento y el esfuerzo que realiza una sociedad sobre la naturaleza dependen de un conjunto de condiciones, tanto ideológicas como materiales, mediante las cuales se construyen los problemas y la manera de tratarlos. En otras palabras, una vez que la reflexión abstracta (el conocimiento ecológico, el pensamiento ambiental) se convierta en acción social, esta acción está determinada por la dinámica global de la sociedad, que asigna una función específica al ambiente como valor y como esfera de administración del Estado. Este hecho relega las leyes de la naturaleza a un segundo plano, y somete la gestión ambiental a las 'leyes sociales' o las cambiantes condiciones de reproducción del cuerpo social. Como anota Harvey (1996), todo proyecto sobre la naturaleza y el ambiente es necesario y simultáneamente es un proyecto de cambio social, y los cambios sociales se realizan dialécticamente.

En términos más concretos, lo anterior sugiere que el entendimiento de la política y gestión ambientales debe buscarse no tanto en las ciencias ambientales y el conocimiento experto, sino en las dinámicas sociales y, más específicamente, en la organización, las estrategias y la intervención del Estado en su conjunto. Esto remite al examen de la gestión ambiental en relación con las reformas neoliberales, y las funciones sociales asignadas al ambiente en el nuevo entorno político, ideológico e institucional del Estado. 
Recientemente, Palacio (2002) formuló una pregunta bastante pertinente no sólo para Colombia sino también para otros países de América Latina. Su cuestionamiento cristaliza una preocupación de fondo de los ambientalistas, en el sentido de si es posible hacer sostenible el desarrollo capitalista, con su energía, expansión y poderío tecnológico voraces e incontenibles. Concretando dicha preocupación en el caso de la política ambiental de Colombia, se pregunta: "¿Habiendo muy poca afinidad entre neoliberalismo y ambientalismo, por qué gobiernos neoliberales han diseñado e implementado tales políticas?" Palacio argumenta la aparente paradoja de que fue el primer gobierno propiamente neoliberal (presidente Gaviria, 1990-1994) el que sentó las bases institucionales de la política ambiental actual, luego consolidada por otros gobiernos igualmente neoliberales, cuando la tendencia general era retirar al Estado de la conducción de los asuntos sociales en favor de las fuerzas del mercado. Este autor encuentra su respuesta principal en la 'órbita internacional', o las presiones y obligaciones mundiales que fue necesario acoger, aunque fuera formalmente, para que el Estado se legitimara en el concierto internacional de naciones, al tiempo que respondía, aunque fuera nominalmente, a influencias e intereses minoritarios dentro del país.

Palacio, como muchos estudiosos del desarrollo sostenible, resalta la producción y su reorganización globalizada. En contraposición, aquí se argumenta que hay que enfocarse más bien en las condiciones generales de producción y en el papel de los Estados en la adecuación y garantía de aquéllas; en otras palabras, en el ambiente como un asunto de gobernabilidad y legitimidad en tiempos de transformación radical en el orden socioespacial. No es casual que se realce la importancia del ambiente precisamente cuando el Estado neoliberal se retira de todos los frentes modernos como garante del bienestar de las poblaciones (Brand, 2001). En Colombia, como en la mayoría de los países, el Estado ha abandonado toda pretensión de garantizar el empleo, ha 'flexibilizado' las condiciones laborales y desmejorado los términos de jubilación, ha dejado de construir vivienda y hasta de administrar el modesto sistema de subsidios; se privatizan paulatinamente el sistema de salud, los servicios públicos y la construcción de vías, se monetiza el sistema de educación, y los programas sociales se concentran o focalizan en los más pobres y desprotegidos sin lograr contrarrestar los crecientes niveles de pobreza y exclusión social. 
Frente a estas contracciones estatales, han crecido dos sectores del Estado en Colombia: el militar y el ambiental. La expansión de los medios de represión, sustentada en la lucha contra la insurgencia, el narcotráfico y la criminalidad, se realiza mediante nuevos mecanismos de vigilancia en los espacios tanto públicos como privados (empresas paraestatales y privadas, circuito cerrado de televisión, 'informantes'), el incremento en las fuerzas públicas de seguridad, la instauración de nuevas unidades antimotines y la ocupación militar de los barrios, todo amparado ahora en la "guerra contra el terrorismo". Sin embargo, la vía represiva puede establecer orden y una gobernabilidad autoritaria, mas no legitimidad. La legitimidad política y la gobernabilidad democrática se construyen en parte por medio del ambiente, al explotar los valores asociados con la naturaleza aparentemente atemporal, autónoma e independiente de las dinámicas económicas; mediante la construcción en el ambiente de sentidos de bienestar, solidaridad, equidad, participación y calidad de vida. Desde esta perspectiva, el ambiente se vuelve no tanto un proyecto ecológico sino más bien un proyecto social con características particulares: la construcción y representación de valores y un campo de regulación social.

Iluso sería pensar que esta contracorriente ambiental se debe únicamente a la fuerza de su propia racionalidad autónoma. Lo que se pone en evidencia, más que una crisis ambiental, es una crisis de legitimidad de los Estados, y especialmente de los Estados locales. Es en las ciudades donde las políticas neoliberales se concretan, donde la falta de empleo y servicios sociales, el desmonte de subsidios y los aumentos en las tarifas, la falta de trabajo y las bajas remuneraciones, las deficiencias habitacionales y las distancias entre grupos sociales, etc. se vuelven sensibles en el espacio, la injusticia social se vuelve tangible y se agudizan los problemas de gobernabilidad. Las administraciones públicas han sido despojadas no sólo de funciones, empresas, instituciones, recursos financieros y capacidad técnica para prestar directamente los servicios básicos que reclaman las poblaciones urbanas, sino también de la capacidad para incidir efectivamente en las condiciones de su prestación privada: su costo, calidad, administración, etc. En tales circunstancias, y lo reconocen perfectamente bien los acosados alcaldes, desaparecen los medios por los cuales los gobiernos locales se legitiman, se agudizan los problemas de gobernabilidad y se esfuman los mecanismos de regulación social que tradicionalmente se han manejado. 
En consecuencia, se abre la posibilidad y se intensifica la necesidad de buscar en el ambiente una nueva esfera de legitimación y gobernabilidad. En el entorno urbano, las agendas ambientales constituyen un campo sensorial y permiten acciones visibles y concretas para dar la sensación de mejoras significativas para el conjunto de los ciudadanos que refuerzan el sentido de solidaridad, cohesión e identidad, al tiempo que establecen nuevos órdenes de regulación del comportamiento ciudadano con sus respectivas responsabilidades, deberes y normas.

La política ambiental en Colombia, dirigida desde 1993 por el Ministerio del Medio Ambiente (convertido en el Ministerio del Medio Ambiente, Vivienda y Desarrollo Territorial en 2002) y las corporaciones autónomas regionales y las ciudades con más de un millón de habitantes, presupone que al mejorar el estado de los recursos naturales y de los espacios donde confluyen, se producirá automáticamente una mejoría en la calidad de vida urbana. Trabajando sobre una agenda basada en la desagregación de los recursos naturales (aire, agua, suelos, biodiversidad), se deja que las relaciones sistémicas del conjunto urbano se encarguen mágicamente de las articulaciones necesarias para construir ciudades sostenibles y materializar las grandes pretensiones sociales asociadas de justicia, equidad, democracia, calidad de vida, etc. Evidentemente no es así. La traducción de la gestión ambiental en un nuevo proyecto urbano es una función de las prácticas políticas y es responsabilidad principal de las administraciones urbanas. Y más aún, no se deriva de una racionalidad ambiental sino de la manera en que el proyecto urbano logre incorporar y movilizar sentidos ambientales en función de su agenda integral de desarrollo y los desafíos de legitimidad y gobernabilidad. Esta es la proposición que se explora a continuación.

\section{Construyendo sentido ambiental: los modos discursivos urbanos}

El modo discursivo se refiere a los recursos lingüísticos, conceptuales y argumentales empleados para construir un sentido particular sobre el ambiente. La construcción de sentido es una obligación de cada ciudad, ya que la política ambiental nacional no aporta sino esquemas generales, insuficientes para la complejidad urbana, que simplifican y soslayan las dificultades y contradicciones inherentes al entorno de las ciudades. Pero, por encima de todo, mientras que la política y la normativa nacionales 
prescriben qué hay que hacer, no responden adecuadamente a la pregunta de por qué.

Este sentido del ambiente y de la acción sobre y en nombre de éste es necesariamente contextual y específico de cada ciudad, por dos consideraciones principales. Por un lado, fuera del caso de la conservación de ecosistemas más o menos prístinos, el reto de la gestión ambiental siempre tiene su énfasis en la modificación de las prácticas sociales que causan el deterioro ambiental, y en estos casos la justificación estrictamente ecológica nunca será suficiente; requiere beneficios sociales explícitos. Especialmente en las ciudades, estos beneficios tienen que integrarse plenamente a lo social y formar parte constitutiva del proyecto urbano. Por otro lado, el carácter político de la gestión ambiental impone una condición práctica, pues lo ambiental tiene que competir con múltiples demandas sobre los siempre insuficientes recursos para la inversión pública, y, en consecuencia, la sostenibilidad ambiental debe mostrarse como algo concreto e inmediato.

Todavía, la legislación colombiana intenta delimitar el ambiente en términos de sus elementos constitutivos naturales: el aire, el agua, el suelo, la fauna y flora, y algunos espacios en los cuales estos elementos se despliegan. Sin embargo, una vez que se deja de objetivar el ambiente, en nuestro caso insertando los recursos naturales en los complejos procesos de urbanización, se diluye irremediablemente en la miríada de actividades y espacios urbanos. Ningún problema ambiental urbano puede tener su solución en la ecología; por más que se intenta amarrar el ambiente a las ciencias naturales, resurge insistentemente como un asunto social.

En todo caso, indagar los significados y sentidos construidos alrededor del concepto de ambiente en cada lugar es una tarea que obliga a ir más allá de la normatividad y las mediciones. Preguntarse por aquellos entendimientos previos que hacen viable tal o cual acción sobre el ambiente implica rastrear en el campo de la política: los planes de desarrollo, los planes de ordenamiento territorial, los enunciados de alcaldes y funcionarios -todos aquellos elementos discursivos que generan sentido-. Más precisamente, requiere analizar los proyectos de ciudad (las formaciones discursivas sobre el desarrollo urbano) en los cuales se construye el sentido local del ambiente: los conceptos y argumentos que lo conectan con el resto de la ciudad, su integración a un proyecto de gobierno y las maneras sutiles de dirigirse a 
partes de la realidad que están fuera del objeto mismo (los recursos naturales) y localizadas más bien en el mundo de lo social. ${ }^{3}$

\subsection{Bogotá: el ambiente como autorregulación}

La construcción del sentido ambiental en la ciudad de Bogotá ha sido determinada por el proyecto de "cultura ciudadana" iniciado en 1995 por el alcalde Antanas Mockus (matemático, filósofo y ex rector de la Universidad Nacional de Colombia). Esta propuesta, orientada a establecer nuevas relaciones entre el gobierno local y la ciudadanía, y sobre todo entre los ciudadanos mismos, forma el contexto imprescindible para entender el ambiente en Bogotá como la esfera donde el ciudadano puede aprender a autorregularse. Por lo tanto, conviene a continuación esbozar las características principales del Programa de Cultura Ciudadana.

En la primera administración de Mockus (1995-1996), el Programa de Cultura Ciudadana fue el eje central de su plan de desarrollo. Se intentaba tratar el problema de la convivencia ciudadana, entendido como la falta de respeto a unas reglas de juego compartidas, y acercar la ley, la moral y la cultura como sistemas de regulación de la acción y la interacción ciudadanas. En su primera administración, Mockus se enfocó en la cultura, y empleó el juego simbólico como medio principal; lo lúdico y lo pedagógico como estrategias, y los imaginarios como objeto (Uribe, 1996). En la medida que se trataba del "conjunto de costumbres, acciones, y reglas mínimas compartidas que generan sentido de pertenencia, facilitan la convivencia y conducen al respeto del patrimonio común y al reconocimiento de los derechos y deberes ciudadanos" (Bogotá, Alcaldía Mayor, 1995, Artículo 6º), el programa tuvo como escenario privilegiado el espacio público, concebido como espacio de interacción entre grupos socioculturales heterogéneos. Los actos simbólicos alrededor de las perinolas y los mimos, las tarjetas ciudadanas y la zanahoria, las jornadas de vacunación contra la

\footnotetext{
${ }^{3}$ Para facilitar la interpretación de los estudios de cada ciudad, conviene precisar que en Colombia los "planes de desarrollo" corresponden a los programas de gobierno de los alcaldes electos e incluyen planes de inversión para su periodo de gobierno, ahora de cuatro años. Por su parte, los "planes de ordenamiento territorial" pretenden establecer visiones más integrales y de largo plazo para la ciudad, y contienen disposiciones sobre usos del suelo, provisión de infraestructura y normas urbanísticas estratégicas y detalladas; su preparación está coordinada por las oficinas de planeación a partir de amplios procesos de participación, y son actualizados periódicamente por las administraciones locales pero aprobados por los consejos municipales; tienen una vigencia de nueve años. Los planes de ordenamiento territorial requieren la aprobación de la autoridad ambiental respectiva.
} 
violencia y el concurso de músicos que cantan en los autobuses se desplegaban en las calles de Bogotá.

En la siguiente administración, del alcalde Enrique Peñalosa, se desbandó el programa de cultura ciudadana como tal, al tiempo que el tema del espacio público recibió un impulso más urbanístico y práctico, que produjo fuertes transformaciones arquitectónicas y espaciales. En el Plan de Desarrollo 1998-2000 Por la Bogotá que queremos, Peñalosa delegó la política ambiental al Departamento Administrativo del Medio Ambiente -DAma, que explotó al máximo el sentido cultural sembrado por Mockus, como veremos más adelante.

En su segundo periodo como alcalde (2001-2003), Mockus retomó la idea de la cultura ciudadana, pero con un fuerte giro hacia la ley y la moral como órdenes de regulación. Legitimándose más en el nuevo clima político e ideológico del país que en la pedagogía y los avances de orden cultural, y recurriendo a las normas legales en vez del juego simbólico, su programa de cultura ciudadana se caracterizó por la imposición de las normas coercitivas. Su alineamiento con el proyecto militarista del presidente Uribe, su apoyo a una declaración de un Estado de excepción, su impulso a nuevos y más severos códigos de policía y de tránsito son apenas algunos ejemplos de este nuevo proyecto cultural con tinte autoritario. ${ }^{4}$

Ahora bien, al principio hubo poca articulación entre este proyecto de cultura ciudadana y el ambiente. Operaban con lógicas distintas. Mientras que, inicialmente, el proyecto de ciudad resaltaba la cultura en su significado cotidiano, el DAMA había heredado la tradición ecologista del anterior Instituto Nacional de los Recursos Naturales Renovables y del Medio Ambiente (Inderena, institución fundada en 1968 y luego reemplazada por el Ministerio del Medio Ambiente en 1993), y había adquirido responsabilidades legales como autoridad ambiental. Uno apelaba al juego y las reglas de juego entre ciudadanos, el otro operaba con base en la ciencia analítica y las leyes naturales y jurídi-

${ }^{4}$ El alcalde Mockus propuso sanciones mucho más fuertes que las eventualmente aprobadas para infractores de las nuevas normas concernientes al espacio público (invasión, ruido, basura). Expandiendo sin límites su proyecto de regulación prohibicionista y moralista, su decisión de desautorizar el consumo de alcohol en la feria de toros a comienzos de 2003 provocó reacciones como la siguiente: "En una nueva demostración de su pedagogía folclórico-autoritaria como método para gobernar a Bogotá, el alcalde Antanas Mockus ha resuelto prohibir la entrada de botas licoreras a la Plaza de Toros de Santamaría. Eso no se llama cultura ciudadana, ni convivencia pacífica, ni experimento de tolerancia. Es, simple y llanamente, una burda alcaldada” (El Tiempo, 2003). 
cas. Trabajando con una agenda ambiental todavía conservacionista que se extendía al espacio público, el Plan de Desarrollo Económico y Social 1995-1997 Formar ciudad resaltó el potencial pedagógico del ambiente refiriéndose a él como campo fértil para la educación, la sensibilización, la participación y la movilización de "la voluntad ciudadana por su gran capacidad de reorientación" (Artículo 9º). Argumentativamente se establece (con un "tal vez") una relación entre el ambiente y el proyecto urbano en términos de su potencial para fomentar el reconocimiento del otro y pensar, colectivamente y a largo plazo, en formar ciudadanos:

Cultura ciudadana y medio ambiente: En ausencia de cultura ciudadana la voluntad de cada persona tiende a orientarse simplemente a la búsqueda de lo que más le conviene. Aunque ésta parece una forma legítima del comportamiento individual, no siempre reconoce diferencias, limitaciones y derechos de los conciudadanos que debieran respetarse [...] Una virtud de la búsqueda del desarrollo sostenible es, tal vez, criticar desde sus mismas raíces el inmediatismo del desarrollo económico y tecnológico de los últimos siglos. Cuidar el ambiente es una forma de asumirse como ciudadano (Bogotá, Alcaldía Mayor, 1995, Exposición de motivos, Decreto 295 de 1 de junio de 1995) (cursivas mías).

A su vez, el plan resalta los elementos naturales como estructurantes potenciales de la ciudad, no sólo en el sentido espacial sino también en el orden de los valores y lo simbólico:

Urbanísticamente, en medio siglo, la ciudad se extenderá a lado y lado del río Bogotá. Los cerros y las rondas del río y los afluentes, junto con el sistema de parques, definirán su estructura. Este patrimonio ambiental recuperado estará integrado al espacio público de la ciudad y será usado con el mismo cuidado y respeto con que usamos el espacio del hogar, el lugar de trabajo o los espacios distinguidos como sagrados por diversas tradiciones.

En la administración del alcalde Peñalosa, el desarrollo sostenible se vuelve un sustrato de su plan de desarrollo, mientras que la construcción de sentido en el ambiente, su potencial para la autorregulación, se realiza discursivamente mediante la gestión ambiental. La estrategia de gestión formulada por la autoridad ambiental, el DAMA, retoma los principios de sentido establecidos por Mockus y los articula al proyecto urbanístico de Peñalosa. Para el Plan de Gestión Ambiental Distrital del DAMA, la estrategia de investigación "sirve para suministrar información científica y técnica aplicada directamente a la toma de decisiones [y ... ] promover el desarrollo conceptual, científico y técnico..."; la estrategia de 
educación "sirve para construir conceptos y valores [y ...] promover cambios voluntarios de actitud y conducta de los distintos actores $[\mathrm{y} . .$.$] enriquecer la cultura de Bogotá y la región con con-$ ceptos, valores y vivencias basados en la riqueza ambiental del territorio..."; la estrategia de participación y descentralización "sirve para fortalecer los mecanismos de autocontrol como base de la gestión ambiental"; y la estrategia de control y vigilancia está dirigida a asegurar el cumplimiento de las normas ambientales y "tiene también un cometido pedagógico, tendiente a fortalecer una serie de mecanismos reguladores de la conducta ambiental individual y colectiva" (Artículo 16 del proyecto de acuerdo mediante el cual se adopta el Plan de Gestión Ambiental del Distrito Capital para el periodo 2001-2010) (cursivas mías).

Es preciso señalar que el acercamiento técnico-ecologista al ambiente que siempre ha caracterizado a Bogotá pudo mantenerse e insertarse en el proyecto de ciudad al proporcionar un sustrato u orden adicional de (auto)regulación, proveniente de las leyes naturales. Los dos discursos (ambiental y cultura ciudadana) se articulan alrededor de la autorregulación. En efecto, el ambiente emerge como un trasfondo implacable para el devenir de la vida social, que "sirve" para exigir normas de conducta fundamentadas en un orden natural. El ambiente alimenta los órdenes de la ley, la moral y la cultura con el orden natural (ecosistémico), al tiempo que sirve de campo ‘neutro' (científico) para resolver algunas de las ambigüedades entre y dentro de aquéllos. Más recientemente, la 'legalidad' del ambiente (las leyes de la naturaleza) proporciona una base de apoyo a la reglamentación coercitiva de las relaciones ciudadanas.

\subsection{Medellín: el ambiente como convivencia pacífica}

Hasta comienzos del nuevo milenio, la ciudad de Medellín había construido un sentido muy particular y efectivo del ambiente como dispositivo de convivencia pacífica. Esta construcción nació luego de varios fenómenos urbanos de la década de 1980, entre ellos la violencia asociada con el narcotráfico, la decadencia de la economía local, la debacle de las obras paralizadas del Metro y escándalos de corrupción. Estos y otros hechos habían sacudido la confianza de la ciudad y reinaba un sentido de vulnerabilidad, sentimientos que se agudizaron aún más con una tragedia ambiental: el deslizamiento de tierra sobre el barrio Villa Tina en 1987, con la pérdida de 300 viviendas y 500 vidas. La relación ambiente- 
vulnerabilidad fue rápidamente consolidada en la conciencia pública mediante el discurso sobre el desarrollo urbano, tal como se ilustra en el espíritu posbrundtland de la siguiente cita:

Unidas a la violencia, el hambre y la descomposición social, el ciudadano del siglo XXI asiste al doloroso espectáculo de la extinción de su medio natural y de su propia vida en un futuro que si no inmediato, muchos han asimilado como irremediable [...] De este foro saldrán entonces prioridades de acción. Es necesario reforzar la acción del Estado mediante la educación y el civismo comunitario. Nos urgen las soluciones y ello no da espera (Medellín, Concejo Municipal, 1989).

Al llegarse a la década de los noventa, una agenda técnica ambiental se había consolidado en la ciudad, pero el problema de la violencia social se intensificaba. En especial, los carteles de la droga iniciaron una campaña de intimidación y terror contra la extradición (a Estados Unidos), y los asesinatos, matanzas y bombas se volvieron sucesos cotidianos. Cuando en el Plan de Desarrollo de 1993 se argumentaba que la ciudad empezaba a salir de lo peor de la violencia y el derrame de sangre, un sentido de alivio permeaba la ciudad, así como una conciencia de la necesidad urgente de reestablecer la armonía social. Se hablaba por primera vez del desarrollo sostenible, en términos adaptados al contexto de violencia de la ciudad:

En Medellín se planificará desde el punto de vista humano y con sentido de responsabilidad con las generaciones futuras, utilizando el criterio de desarrollo sostenible, para que en la medida en que se atiendan las necesidades presentes, se busque subsanar las carencias del pasado y se generen condiciones que garanticen la vida en paz y prosperidad para el futuro de los medellinenses [...] La ciudad se regirá por los principios de respeto por la vida humana y de todo otro tipo; el desarrollo integral de los medellinenses, y por ende de la ciudad, deberá darse en perfecta armonía con los demás seres humanos y con el ecosistema que nos rodea (Medellín, Concejo Municipal, 1993: 97).

De ahí en adelante, el ambiente se convirtió en un dispositivo para la reconstitución conceptual de un sentido de unidad y cohesión, una metáfora para la convivencia. El ambiente se asoció discursivamente con las nociones de equidad, seguridad, coexistencia pacífica, racionalidad y armonía: todas las calidades tan notoriamente ausentes en la vida social de la ciudad en ese entonces. La instalación del Instituto Mi Río en 1992, para manejar los problemas relacionados con el río principal y numerosos afluentes torrenciales que atraviesan la ciudad, llevaba ese men- 
saje a los barrios mediante campañas y obras urbanísticas concretas. Se profundizó en el manejo técnico del ambiente y se 'enverdeció' la agenda urbana en general, con la prioridad espacial a laderas y quebradas, la forestación masiva y la conversión de los alrededores del río Medellín - una autopista- en el principal espacio público de la ciudad. Un esfuerzo discursivo y urbanístico de una década estableció una asociación creíble entre ambiente y convivencia urbana.

Más tarde, durante la administración del alcalde Gómez Martínez (1998-2000), el espacio público empezó a plantearse como fuente alternativa de cohesión para los habitantes de una ciudad en "estado de posguerra". Sin embargo, el mismo alcalde fue muy sensible al poder simbólico del ambiente al ubicar en la tradición regional "paisa" del buen manejo de la casa o, más coyunturalmente, en su potencial para generar empleo. Los recursos discursivos y las instituciones disponibles permitieron seguir explotándolo plenamente.

En el nuevo milenio, y con la administración del alcalde Luis Pérez (2001-2003), tanto el gobierno como los planificadores efectivamente abandonaron la construcción de sentido en el ambiente. En el Plan de Desarrollo 2001-2003 Medellín competitiva, el medio natural y la ecología dejaron de ser utilizados como referencias para la convivencia entre los ciudadanos, al ser reemplazados por el espacio público como 'estructurante de ciudad':

La ciudad se enseña y enseña en sus calles. Es necesario, por ello, permitir palparla y vivirla como escenario permanente de aprendizaje y convivencia, mas no de supervivencia. Nunca debemos dejar de sorprendernos con lo nuestro: es necesario volvernos turistas en nuestra propia ciudad [... La ciudad tiene bellos laboratorios para la práctica de la vida. Las calles, los graneros, los escenarios para el juego y el tiempo libre, los museos y demás espacios para la difusión científica, los parques y los lugares de encuentro y conversación. Todos ellos necesitan un hilo conductor para que adquieran su acento educativo (Medellín, Alcaldía, 2001).

Se argumenta que "la mayor urgencia de nuestra sociedad es encontrar una nueva forma de mejorar la vida”, enunciado en el cual está implícito el abandono de la ecología para tal propósito, sin que se arme una alternativa equivalente. La "nueva urbanidad" que se anuncia adquiere significados más concretos:

La nueva urbanidad reclama nuevos valores de conducta que fortifiquen la convivencia. No podemos tolerar conductores embriagados, 
en su doble condición de violadores de la norma y homicidas potenciales; ciudadanos perturbadores de la tranquilidad de los vecinos; personas que no toleran la diferencia con el otro; hinchas de fútbol que agreden al contrario por el solo hecho de ser contrario; funcionarios públicos especializados en acelerar la demora para atender al usuario... (Medellín, Alcaldía, 2001).

En el planteamiento de una "revolución de la cultura urbana”, la administración municipal abandona, discursivamente, el potencial semántico de la naturaleza y, con ello, cualquier referencia metafórica, para caer en lo frágilmente humano que, desde luego, no aguanta la volatilidad de la realidad urbana. En consecuencia, el ambiente queda reducido a una agenda técnica en manos del Área Metropolitana del Valle de Aburrá como autoridad ambiental. Además, en la reestructuración del municipio en 2001, el Instituto Mi Río, principal animador del sentido ambiental durante los años noventa, fue disuelto para reaparecer más burocráticamente como la Subsecretaría Metrorío en la nueva Secretaría del Medio Ambiente, a su vez inmovilizada durante un año por la falta de un titular en propiedad. Es decir, en el marco del nuevo proyecto de ciudad con su abandono semántico del ambiente, la desactivación del discurso y el desmantelamiento de las instituciones sucedieron simultáneamente.

En un lapso de dos o tres años, la ciudad vio cómo se desvanecía el sentido social del ambiente, pacientemente construido en una década, para dejar en su lugar un creciente autoritarismo técnico y normativo. Con ello, el discurso ambiental se volvió introspectivo, campo de expertos y de instituciones especializadas, recelos entre organizaciones, imposiciones reglamentarias. Es pertinente preguntar si en el caso de Medellín, el sentido ambiental (de armonía y convivencia) fue abandonado o si más bien se agotó. De todas maneras, el sepulcro simbólico sucedió en octubre de 2002, cuando la fuerza pública entró con todo (tropas, tanques y helicópteros) a la Comuna 13 para reprimir la violencia allí reinante, cuando antes lo hubiera hecho con obras hidráulicas y árboles. ${ }^{5}$

${ }^{5}$ La Comuna 13 de Medellín es un sector de bajos ingresos y, como muchos, escenario de luchas entre grupos ilegales armados -combinaciones inestables de milicias guerrilleras, paramilitares, narcotraficantes, delincuencia común y bandas juveniles- para el control territorial. La estrategia ambiental de los años noventa tuvo como fin, precisamente, mediatizar y manejar la violencia inherente a tales situaciones. A partir de 2002, y al amparo de las directrices del nuevo gobierno nacional, se optó por soluciones militares; la operación en la Comuna 13 fue la primera. El nuevo gobierno municipal de 2004 está intentando rescatar la negociación política. 


\subsection{Cali: el ambiente como campo cognoscitivo}

En la ciudad de Cali es más difícil identificar algún sentido social del ambiente. Aunque hubo fuertes movimientos ecologistas en la región en las décadas de 1960 y 1970, éstos se relacionaban sobre todo con la explotación agroindustrial de la región. Pocas huellas dejaron en la ciudad, y tal vez su legado más significativo ha sido una preocupación ambiental centrada en los ecosistemas. Ciertamente, la ignorancia -el desconocimiento y la despreocupaciónforma un componente central del discurso ambiental. Se argumenta que esta 'ignorancia' del ciudadano caleño, puesta en plena evidencia en relación con el ambiente, también es aplicable a su relación con la ciudad en todas sus dimensiones:

Muchos de los habitantes de Cali no conocemos nuestra ciudad, no sabemos cuántos somos, o cómo estamos distribuidos en el territorio, o cuánto consumimos diariamente o las cantidades de contaminantes y desechos que arrojamos al ambiente. Si no conocemos el espacio en el cual vivimos, no podemos esperar que lo defendamos, cuidemos y transformemos [...] basta preguntar a cualquier grupo de caleños: ¿Cuántos ríos cruzan la ciudad? para encontrar respuestas dubitativas que tímidamente anotan... ¿dos?... ¿tres?... ¿cuatro?... Con frecuencia olvidamos nuestro Cali, nuestro Cauca, nuestro Agaucatal, nuestro Cañaveralejo, nuestro Pance, nuestro Lili y nuestro Meléndez. Esta cartilla es una invitación a conocer más de la ciudad [...] es una invitación a encontrarnos con Santiago de Cali para que nuestras actitudes hacia ella cambien positivamente y resurja en cada uno de nosotros el compromiso de construir la ciudad que queremos (Cali, DAGMA, 1999).

La educación ambiental se volvió desde el principio un eje central de la autoridad ambiental, el Departamento Administrativo de Gestión del Medio Amiente (DAGMA), primero en términos de información, y luego de sensibilización y participación. Sin embargo, el conocimiento (sistemático y ecológico) parecía ser la base y condición imprescindibles para ejercer el derecho a participar. Siendo una estrategia potencialmente excluyente y estigmatizadora, había que acompañarla de estrategias pedagógicas que vacilaban entre la reprimenda, por un lado, y el aliento, por otro. Por ejemplo, una cartilla sobre silvicultura urbana lleva el subtítulo de "acciones de la gente decente para volver a creer" (cursivas mías); y en la introducción el alcalde comenta: "Los caleños deben comprender que el mal manejo frente al cuidado y preservación de la vegetación arbórea ha obstruido el correcto funcionamiento de éstos en el entorno" (Cali, DAGMA, 2001). En 
otros casos, se asume una actitud más tolerante y abierta a la tradición cultural del caleño:

En nuestro caso específico, Santiago de Cali, como espacio social, cultural y económico, como ciudad y mujer habitada, requiere y merece una política educativa y unas prácticas de educación ambiental que impulsen formas de crecimiento, sostenimiento y transformación basadas en lo que somos: Una ciudad hidráulica, una ciudad migrante, una ciudad pluriétnica, una ciudad telúrica, coqueta y cálida (El País, 1999: 29).

En todo caso, el énfasis en el conocimiento lleva a la tendencia de utilizar el lenguaje técnico, la cuantificación y la descripción estadística. No es que los datos sean irrelevantes, sino que muestran una dependencia exagerada en ellos para describir los fenómenos ambientales y una carencia de sentido social. Estos datos pueden delimitar o dimensionar el problema, como en las siguientes citas, sin ningún intento de asociarle el ambiente con valores o significados que vayan más allá de una fría presentación de los hechos:

Complementario al déficit habitacional, el estudio realizado por el CENAC en julio de 2000 encontró problemas en el entorno de las viviendas. En efecto, de la totalidad de hogares de la ciudad, 359.337 se encuentran en déficit de localización (67.2\%), especialmente afectados por problemas que limitan el desarrollo social, que afecta a más de la mitad de los hogares de la ciudad. El 7.6\% está en riesgo por movimientos en masa, el $3.8 \%$ en riesgo de avalancha y el $1.5 \%$ por inundación (Cali, Alcaldía, 2001: 12).

Hay ciudades en el mundo como Nueva York, París y Moscú que cuentan con más de 10 árboles por habitante. Cali tiene 7 habitantes por árbol, se requiere que en una ciudad haya siquiera 700.000 árboles y sólo hay 285.000 en los espacios verdes públicos. Según la Organización Mundial de la Salud se requiere 3 árboles por habitante y 8 árboles por cuadra, mínimo, para la generación de oxígeno (Cali, DAGMA, 2001).

En consecuencia, el ambiente se presenta sobre todo como un campo de conocimiento sistemático, y por lo tanto como un asunto exigente y potencialmente excluyente, no sólo para el ciudadano sino también para la administración de la ciudad. Las alcaldías parecen no haber tenido mayor interés en entenderlo en estos términos, ni haber encontrado maneras alternativas (no sistemáticas y no ecológicas) de dotar al ambiente de sentido. Además, esta comprensión técnico-científica del ambiente se prestaba, irónicamente, para propiciar conflictos entre el DAG$\mathrm{MA}$, otras entidades públicas y organizaciones no gubernamenta- 
les competentes en el campo ambiental. Estos conflictos alrededor del conocimiento sólo sirvieron para enredar aún más el ambiente en un debate técnico enrarecido, por lo demás poco importante para las administraciones locales, y eventualmente aburridor para el ciudadano común y corriente.

Como demostración de ello, el Plan de Desarrollo de Santiago de Cali 1998-2001 parecía deshacerse lo más someramente posible del tema ambiental. Se planteó como un complemento al Plan de Desarrollo Económico y Social, y asunto delegado al Plan de Ordenamiento Territorial. Se propuso que el tema ambiental era importante "no sólo por ser un problema ético, sino porque también lo ambiental era ante todo un problema económico y social". No se especifica cómo y por qué, y se cae irremediablemente en las viejas nociones conservacionistas de la ciudad:

El Plan de Desarrollo se basa en el concepto moderno del Desarrollo Sostenible el cual enfatiza en la conservación del medio ambiente como un activo importante pero limitado y finito. Se propende por una nueva cultura del desarrollo, que haga posible la participación y gestión ambiental efectiva, que prevenga y minimice los daños ambientales (Cali, Alcaldía, 1998).

El Plan de Ordenamiento Territorial tampoco respondió al reto de construir sentido. A pesar de que el ambiente (el análisis de las condiciones naturales del territorio) constituye el fundamento del plan, no se logra transformar una base de información sobre las condiciones del territorio en una propuesta de ciudad. El ambiente no figura entre los "nudos críticos" de la ciudad, ni logra articularse a los problemas principales planteados: el deterioro económico, la desintegración del tejido social y la desconfianza en la administración pública. Aun en relación con la vida urbana, no logra concretarse una relación del ambiente con los problemas vivos y agudos de la ciudad:

[...] el aumento de la población, su expansión urbanística, el auge e implicaciones del narcotráfico en la vida social, política y económica del municipio han incidido en la transformación de los comportamientos de la población, no sólo en sus consumos sino en sus formas de interacción y convivencia, cada vez más marcadas por el individualismo, la fragmentación de intereses y conductas, la incapacidad de construir proyectos comunes a partir del diálogo y la comunicación pluralista y, como ya se vio, por la violencia (Cali, Alcaldía, 2001: 13).

En las otras ciudades se logró una articulación significativa mediante el discurso sobre la ciudad; se formó sentido en el 
ambiente. En Cali, el sentido se ha buscado casi exclusivamente en el conocimiento técnico-científico, terreno estéril para la movilización social a lo largo de la historia del urbanismo.

\subsection{Barranquilla: el ambiente como disciplina social}

En el caso de Barranquilla, el aspecto de la vida social que se resalta en el discurso ambiental es el de la indisciplina de los ciudadanos. En la medida que se plantean los problemas graves de Barranquilla en términos de la indiferencia y el desarraigo de los ciudadanos, por un lado, y del comportamiento individualista y el irrespeto por las normas de vida en sociedad, por el otro lado, se vuelven los marcos referenciales para entender conceptual y argumentativamente el ambiente. Éste emerge, entonces, de un discurso urbano no ecológico, construido más bien alrededor de las características culturales, tanto históricas como actuales, de la ciudad.

En el ejercicio de participación que precedió la formulación de este plan, los diferentes actores convocados por la Alcaldía identificaron como uno de los mayores obstáculos al desarrollo de la ciudad la falta de sentido de pertenencia de los habitantes de Barranquilla respecto a la ciudad en la que habitan, señalando además la falta de solidaridad con los propósitos colectivos, la ausencia de una cultura ciudadana, la apatía y la pasividad entre los problemas más recurrentes (Barranquilla, Alcaldía, 2001: 18).

También se debe anotar aquí el carácter híbrido de la idiosincrasia Barranquillera, que en muchos casos resulta positiva -manifestaciones folclóricas- y en otros no tanto, porque existe una indiferencia y una actitud de desarraigo en todo lo que tiene que ver con la problemática de lo público, que la ciudad vive una gran paradoja frente a su 'carácter anfibio' (Barranquilla, Alcaldía, 2000, t. 1: 58).

Por un lado, el ambiente se ubica en el discurso sobre la historia y cultura de la ciudad, y en ese contexto, la prioridad es la de re-conocer las relaciones de la ciudad con el río Magdalena y la época gloriosa de la primera mitad del siglo xx. Recuperar esa cultura orgullosa y cosmopolita de los tiempos pasados configura el referente para entender el ambiente y su importancia. La propuesta espacial del Plan de Ordenamiento Territorial del año 2000 propone un modelo precisamente en esos términos:

El modelo busca generar un proceso de "encuentro de la ciudad con el Río Magdalena” [...] Propicia, urbanísticamente, la relación ciudad- 
río para permitir un reencuentro con el recurso natural que le dio sentido, viabilidad y vocación a Barranquilla en primera instancia como ciudad portuaria, luego comercial y posteriormente industrial, insertándola en los valores paisajísticos, naturales y culturales de la ciudad, para el disfrute abierto y espontáneo de sus habitantes, sin que ello represente una barrera para las aspiraciones de su uso como recurso económico estratégico no sólo local sino regional y nacional. La sana convivencia y complementariedad constituyen principios sobre los cuales debe regirse la nueva vocación urbana de la ribera occidental del Río Magdalena (Barranquilla, Alcaldía, 2000: t. 2: 25).

Por otro lado están los males culturales del presente: el pobre sentido de lo público y el comportamiento inculto de los ciudadanos en sus momentos 'no folclóricos'. A su vez, esto dirige la atención hacia aquella dimensión de la ciudad en la cual sus pobladores se encuentran e interactúan: el espacio público:

[...] tradicionalmente caracterizado por la inobservancia de las normas, la invasión de las calles para actividades económicas, la generación de barrios espontáneos, deterioro de los parques y zonas verdes, deterioro de sectores urbanos producto de la escasa atención de las administraciones, deterioro de los sectores de valor patrimonial son, entre otros, algunos aspectos que tipifican el grado de abandono de componentes esenciales de lo público (Barranquilla, Alcaldía, 2000, t. 2: 33).

Y si hubiera alguna duda sobre los peligros inminentes:

Los parques generalmente son zonas privadas de gamines, indigentes, drogadictos y delincuentes, mientras que los urbanizadores incumplen constantemente con las áreas de cesión obligatoria (Barranquilla, Alcaldía, 2000 t. 1: 117).

Estos temas también figuran fuertemente entre las preocupaciones de la autoridad ambiental de la ciudad -en el caso de Barranquilla, denominada el Departamento Administrativo Distrital del Medio Ambiente (Dadima)-, pues la indisciplina del barranquillero parece extenderse a todas las clases sociales y sectores económicos, concepto divulgado también por los medios de comunicación locales en relación con los problemas de contaminación sonora y visual:

Es tal el nivel de bulla o ruido que persiste en algunos sectores de Barranquilla que el Dadima tiene una oficina repleta de bafles, altoparlantes y megáfonos. 'No sabemos qué hacer con tanto bafle', asegura [un funcionario del Dadima] [...] Explica que por su misma cultura el barranquillero habla alto y cuando se encuentra con una o dos personas, entonces se vuelve bochinche [...] Las estadísticas revelan que el 
mayor número de quejas ante el Dadima se producen contra los miembros de algunas religiones que a diario invaden parques y otras zonas públicas para predicar y orar [...] y quienes viven en los estratos $3,4,5$ y 6 son los que más llaman a reportar inconformidad por ruidos [...] persisten problemas puntuales como es el caso de los carromuleros con altoparlantes, los vehículos parqueados en las licorerías con pasacintas a todo volumen y el ruido que a diario ocasionan talleres de mecánica y similares en zonas residenciales (El Heraldo, 2001).

A Barranquilla no le cabe una valla, una pasacalle o cualquier otro elemento utilizado para la publicidad visual. Y si quiere comprobarlo, sólo dese una vuelta por sectores comerciales estratégicos del centro, el Sur o el Norte en donde podrá detectar la "invasión” a la que estamos sometidos por negocios de todo tipo. Es tal el caos, que en todo el país somos la ciudad con la mayor contaminación visual, por encima de otras capitales como Bogotá, Medellín y Cali (El Heraldo, 2003a).

Un aspecto particular de Barranquilla concierne a esta autocrítica abierta y ampliamente compartida, en la cual se reconocen ciertos 'excesos' de comportamiento en relación con el ambiente y el espacio público, frente a lo cual existe una disposición de cambiar y someterse a sanciones en el caso de infracciones, actitud compartida no sólo por funcionarios públicos y medios de comunicación, sino también por taxistas y vendedores ambulantes. Entonces, llamadas como la siguiente, para una mayor disciplina ciudadana, surgen con toda naturalidad:

Más colaboración ciudadana y mano fuerte por parte de las autoridades pidieron ayer la Triple A [empresa privada de prestación de servicios públicos domiciliarios] y el Dadima para evitar la proliferación de basuras en los caños de Barranquillita [...] La problemática de los caños tal como la ha manejado la Alcaldía de Barranquilla con un proceso de dragado y mantenimiento es un aspecto. El otro aspecto que incluye mantenimiento permanente, es el mal comportamiento de la ciudadanía [...] hace falta que todos los barranquilleros se involucren con el problema de la limpieza y el aseo de la ciudad [...] Seguiremos llevando nuestros mensajes claros y concientizadores [...] [pero también] hace falta más apoyo policivo y sanciones para los infractores que arrojan basura en los sitios públicos (El Heraldo, 2003b).

No es que se descuiden del todo los problemas ambientales materiales, sino que éstos se subordinan al argumento general de la necesidad de límites y restricciones, normas y sanciones sobre el comportamiento ciudadano en relación con el ambiente. En Barranquilla el ambiente se construye como algo experiencial, marginado de las mediciones y la técnica. Una relación vital con la naturaleza como expresión de la cultura costeña, pero ya ma- 
nipulada por las autoridades tanto ambientales como de otras áreas, en su proyecto de reglamentar la vida urbana y disciplinar el comportamiento de los ciudadanos, incluso con su complacencia ambigua.

\subsection{Sintesis}

En esta sección resaltamos el sentido social construido sobre el ambiente en cada ciudad, o por lo menos sus rasgos principales. No son, por supuesto, los sentidos únicos. En todas partes se habla del ambiente en términos de calidad de vida, disfrute estético, salubridad, responsabilidad intergeneracional y demás lugares comunes, que sirven como soporte general al discurso ambiental. Tampoco son los sentidos típicos que propone el discurso ambiental en sus planteamientos formales que enclaustran y amarran el ambiente al mundo de la naturaleza y las ciencias naturales, sin darse cuenta de que se trata de un proyecto social cuya vitalidad está determinada por las posibilidades de articulación a las complejidades y contradicciones de los conjuntos urbanos. Fue necesario, entonces, buscar los sentidos ambientales en los discursos globales de cada ciudad. Allí, en el discurso político y planificador, se define el lugar del ambiente en relación con el conjunto de problemas urbanos: su lugar en el entendimiento, la definición y la administración de los fenómenos urbanos, y, sobre todo, en la regulación de las relaciones entre los ciudadanos y entre éstos con los gobiernos locales.

Dicha regulación tiene sus particularidades en cada ciudad, conforme a las tradiciones culturales, trayectorias urbanas y estilos de gobierno respectivos. En Bogotá, el ambiente encaja en el proyecto de autorregulación ciudadana; en Barranquilla, en la búsqueda del acatamiento a normas de comportamiento social y la disciplina ciudadana; en Medellín se concreta como metáfora para la convivencia ciudadana, por lo menos hasta hace poco; únicamente en Cali existe cierto vacío significacional. En verdad se trata más de un 'encajamiento', pues se ha argumentado que el sentido del ambiente se construye discursivamente en el debate general sobre las ciudades; en otras palabras, que lo que aparece como una articulación programática entre las instituciones de gobierno realmente es producto de una comprensión más profunda o formación discursiva que establece, previamente, la manera de entender y de dar prioridad a las posibilidades de actuación sobre la ciudad en toda su complejidad. 
Las especificidades del sentido ambiental en cada ciudad deben entenderse como una gran fortaleza, pues aseguran que el ambiente tenga la vitalidad cultural y la potencia política necesarias para traducir los lugares comunes del ambiente en realidades socioespaciales. Cuando no logra construirse sentido, como en el caso de Cali, el ambiente se presenta apenas como un objeto externo e inerme, carente de significado e importancia. Por otro lado, los sentidos particulares conducen a 'irregularidades' en la gestión ambiental, en el sentido de resaltar ciertos aspectos y descuidar otros, lógicas distintas de actuación, el incumplimiento de funciones normativas del sistema nacional ambiental, aparentes distorsiones institucionales, etcétera.

Frente a esta riqueza esencial del ambiente, existe también una tendencia en todas las ciudades hacia la regulación normativa y coercitiva: el entendimiento empobrecido del ambiente como dispositivo de autoridad; una tendencia homogeneizante orquestada por el ahora Ministerio del Ambiente, Vivienda y Desarrollo Territorial e implantada por las instituciones ambientales definidas en sí como 'autoridad', que se impone cada vez más con fuerza de ley y poderío técnico sobre las demás instituciones locales. Analizaremos esto en la siguiente sección.

\section{La movilización de sentido: instituciones, proyectos espaciales y gestión de los recursos naturales}

En la sección anterior se exploró cómo en cada una de las ciudades estudiadas se construye sentido respecto al ambiente por medio del discurso urbano. Se intentó ilustrar que este sentido no depende de una racionalidad ecológica universal ni de la existencia de problemas ambientales objetivos, sino de la manera en que, en cada ciudad, logren construirse en el ambiente respuestas al conjunto de problemas urbanos, y que esta construcción no está libre de ataduras sino que está condicionada por la manera en que cada ciudad habla de sí misma; en otras palabras, de las tradiciones político-culturales y las coyunturas socioeconómicas de las ciudades. En esta sección pretende comentarse, aunque sea someramente, la importancia de las instituciones ambientales en la movilización de tales sentidos, pues es por medio de las instituciones especializadas que el discurso planificador, las palabras, se convierten en una realidad tangible y logran hacerse sentir en la experiencia ciudadana. Además, como lo han analizado Brenner y Theodore (2002), las instituciones adquie- 
ren una importancia crítica en la re-regulación de la vida social para el Estado neoliberal, en un proceso permanente de ajuste y experimentación institucional para encontrar arreglos adecuados a los cambiantes desafíos de control del espacio.

En Colombia, las instituciones ambientales fueron instauradas por medio de la Ley 99 de 1993 que estableció el llamado Sistema Nacional Ambiental, regido por el nuevo Ministerio del Medio Ambiente y con institutos de investigación de orden nacional y corporaciones autónomas regionales actuando como autoridades ambientales, mientras que las entidades territoriales (departamentos y municipios) adquirieron responsabilidades ejecutorias subsidiarias. Este complejo sistema, jerárquico en su estructura pero horizontalmente abierto a todo tipo de organización social, requirió la formación de nuevas entidades y relaciones de coordinación. La ley concibió este sistema ambiental como la interacción racional y armoniosa de instituciones y organizaciones como si estuvieran desprovistas de poder y libres de conflictos. Sin embargo, la institucionalidad ambiental tuvo que insertarse y crecer dentro de la compleja realidad políticoadministrativa de las ciudades y regiones, para convertirse en una esfera de competencia por el control del ambiente que involucra intereses adicionales a los ambientales en múltiples niveles: el control del sentido del ambiente mediante el discurso, el control de presupuestos y status institucional, y el control de instrumentos de regulación social.

El resultado ha sido, a pesar de las intenciones homogeneizantes de esa ley, una gran diversidad organizacional y funcional en el ámbito urbano. Esta diversidad va desde la ubicación de la autoridad ambiental (caso excepcional de Medellín y su área metropolitana) hasta grandes variaciones en atención a las diferentes responsabilidades ambientales atribuidas legalmente a las ciudades. Más aún, pudo comprobarse que no es la capacidad técnica y financiera de las instituciones ambientales la que determina el éxito de la gestión ambiental, sino que el desempeño de ellas depende de la elaboración previa de sentidos políticos y sociales en el ambiente, por medio de su integración al discurso urbano global y el proyecto de ciudad (lograda con éxito en las ciudades de Bogotá y Barranquilla, desdibujándose en Medellín, y carente en Cali). Adicionalmente, para que la movilización de sentido se realice efectivamente, es fundamental que: 
- Las demás entidades cumplan adecuadamente sus responsabilidades ambientales. Esto es especialmente relevante en cuanto al saneamiento ambiental básico, ya que se libera a las autoridades ambientales para dedicarse a asuntos menos infraestructurales y más relacionados con el espacio urbano y la vida ciudadana experiencial.

- Los conflictos interinstitucionales se mantengan dentro de unos límites que no desdibujen la importancia general del ambiente. Los conflictos institucionales pueden incluso resaltar y sostener el perfil político positivo del tema para la conducción de los asuntos urbanos.

- La inestabilidad institucional propia de las reformas permanentes del Estado neoliberal no socave la movilización constante del sentido ambiental mediante la interrupción de programas. El sentido ambiental tiene que reproducirse permanentemente, sobre todo en relación con los graves problemas sociales que sufren los sectores populares de las ciudades.

- La gestión ambiental responda a las culturas regionales por encima de las normas técnicas, pues las primeras son las fuentes de los códigos simbólicos que dan viabilidad tanto la construcción de sentido como a las intervenciones prácticas ambientales. Se requiere la articulación ingeniosa entre los valores culturales de la región y las normas ambientales universales.

De manera semejante, la movilización de sentido ambiental por medio de intervenciones espaciales también es bastante heterogénea. La gestión de los recursos naturales conlleva necesariamente a la gestión del espacio y a modificaciones concretas en la construcción, organización y regulación del espacio urbano, cuya concreción en cada ciudad también emerge de los discursos urbanos mas no de una preocupación ecológica de tipo abstracto. En esta producción variable intervienen no sólo la habilidad discursiva de traducir los recursos naturales o 'problemas ambientales' en proyectos urbanos, sino también las tradiciones urbanísticas y la permanencia de temas, las valoraciones culturales, las especificidades geográficas y la capacidad financiera y ejecutora de los municipios y sus entidades descentralizadas. Estas variables no deben entenderse como condiciones funcionales sino más bien como factores que modulan las formas de construcción de sentido. Por ejemplo, en Bogotá la incidencia urbanística se 
concentra en el espacio público, con intervenciones caracterizadas por la elaboración de escenas urbanas, apoyadas en una racionalidad ecológica pero dirigidas hacia la cultura ciudadana 'formalizada' y el espectáculo: la dramatización de la vida urbana. En contraste, el enfoque e impacto urbanísticos en Medellín han sido más enraizados en los sectores populares y la convivencia ciudadana, con incidencia en los barrios pobres y la calle común y corriente. En Barranquilla, la preponderancia del ambiente como tema en la espacialidad de la ciudad está todavía por verse, y ruega por una interpretación local y cultural de lo que podría ser una 'ciudad sostenible' en la costa caribeña. En Cali, el impacto del ambiente es lo que se produjo años atrás, y la incidencia de una estrategia y gestión ambiental contemporánea es poco evidente.

No obstante tanto esfuerzo realizado sobre y en nombre del ambiente, la información sobre el estado de los recursos naturales es todavía precaria, y sujeta a una permanente contestación. Las instituciones, las tecnologías de medición y los sistemas de información están todavía en construcción; la cantidad de información es extensa y las fuentes diversas, la calidad y la cobertura de la información son variables e incompletas. Desde luego, el acercamiento técnico e ingenieril al ambiente, su objetivación y cuantificación, es simplemente una manera particular de describirlo y darle contenido -el modo científico del discurso ambiental-, y como tal hace una contribución secundaria pero significativa, que interactúa estrechamente con otras modalidades discursivas para generar 'efectos de verdad'.

Finalmente, interesa contrastar los argumentos sobre la importancia y valor del ambiente con el esfuerzo presupuestal o gasto ambiental efectivamente realizado en este sector: la amplitud del discurso frente al monto del dinero gastado. ¿Qué relación existe entre el ambiente como 'indicador' de la calidad de vida urbana y el dinero público invertido en él? ¿Constituye una esfera para la redistribución social del ingreso? El gasto ambiental realizado por las autoridades correspondientes es sumamente bajo, oscila entre $\$ 8,727$ y $\$ 1,075$ (aproximadamente us $\$ 3.00$ y us $\$ 0.40$ ) per cápita/año en las cuatro ciudades estudiadas, incluso con una tendencia a disminuir entre 1999-2001. Otra aproximación al gasto ambiental es por medio de la inversión ambiental (sectorial) presupuestada en los planes de desarrollo de las ciudades (2001-2003), que incluye la participación de las diferentes entidades públicas locales. No obstante la necesidad 
de interpretar la formulación de los presupuestos con cierta cautela, puede deducirse que la inversión ambiental nominal constituye un aspecto significativo del presupuesto de las entidades territoriales. En Bogotá, la inversión ambiental presupuestada (4.6\% del presupuesto total) es superior a la de "cultura, recreación y deporte" (3.1\%) y "vivienda y desarrollo urbano" $(2.6 \%)$; en Medellín, la inversión ambiental (7.3\%) es inferior a la de "vivienda y hábitat" (13.5\%), pero superior a la de "espacio público" (5.7\%) y "cultura, recreación y deporte" (0.6\%); y en Cali $(12.4 \%)$ es superior a la de "cultura, recreación y deporte" (2.8\%), "vivienda" (0.6\%) y "gestión urbanística" (0.07\%). Es importante señalar que se trata de los presupuestos públicos, quedan excluidas las inversiones de las empresas privadas, incluyendo aquellas que prestan servicios de saneamiento ambiental (acueducto, alcantarillado, aseo).

\section{Conclusiones}

El acercamiento a las propuestas ambientales urbanas desde el análisis del discurso permite entenderlas como representaciones de la realidad imbuidas de intereses y poder, como estrategias políticas de desarrollo. Desde esta perspectiva del análisis del discurso, la realidad no es algo externo para analizar mediante instrumentos neutros; la realidad y el análisis, los problemas y las metas se construyen simultáneamente. Por lo tanto, las estrategias ambientales como discursos dependen del contexto y las prácticas discursivas que producen, reproducen y transforman el sentido otorgado a la realidad; la consistencia lógica no es un requisito imprescindible, es más importante el efecto de verdad que el discurso propicia, y de ahí su capacidad de legitimación gubernamental y de regulación social.

Por esta razón, el éxito de la gestión ambiental urbana no depende del análisis riguroso del estado de los recursos naturales ni de las instituciones especializadas que los administran, sino de la capacidad de las administraciones urbanas de armar un proyecto de ciudad que articule e integre el ambiente. En la medida que los desafíos de legitimidad de los gobiernos y de regulación de las poblaciones surgen de los efectos de la globalización y las limitaciones del Estado neoliberal, la construcción de sentido ambiental adquiere el carácter general de contrapeso. La gestión ambiental no tiene que justificarse ni evaluarse con base en resultados tangibles, en cuanto al mejoramiento del estado de los 
recursos naturales. Sobre todo, los discursos ambientales construyen valores opuestos a aquellos que operan en la esfera de la economía y la competitividad como vector principal del desarrollo: a la competencia, la eficiencia, la productividad, la ganancia y el interés privado se contrapone, ambientalmente, la cooperación desinteresada, el ocio, el disfrute, los valores humanos y el interés colectivo. A continuación sintetizamos los rasgos principales de este fenómeno.

Recursos institucionales y financieros: En primer lugar conviene señalar el hecho de que el ambiente es la única esfera, junto con la seguridad, de expansión estatal. Se han establecido no sólo nuevas instituciones, sino también fuentes de financiación propias. Las estrategias ambientales demuestran una tendencia de autofinanciación con una creciente importancia en relación con el gasto social general, y de gran significado para las administraciones urbanas. No se trata de grandes cantidades de dinero, pero sí de gran impacto socioespacial. La inversión ambiental total es modesta en términos reales (aproximadamente us $\$ 8.00$ por habitante/año en Bogotá, us $\$ 12.00$ en Medellín y us\$6.00 en Cali, según los presupuestos de los planes de desarrollo), pero en Bogotá y Cali ésta supera a la inversión en los rubros de "vivienda y desarrollo urbano" y "cultura, recreación y deporte". Las autoridades ambientales urbanas manejan presupuestos aún más precarios (entre us $\$ 3.00$ por habitante/año en Bogotá, y us $\$ 0.40$ por habitante/año en Cali), pero sus programas y proyectos impactan directamente la vida ciudadana. En otras palabras, las ciudades encuentran en el ambiente instrumentos y medios relativamente fuertes, en el contexto neoliberal, para construir bienestar urbano.

La implantación de valores: Se establecen en el ambiente valores sociales que contrastan con los valores inherentes a la competitividad y contrarrestan los fenómenos sociales asociados con ella. En cada ciudad se elabora un 'modo discursivo' sobre el ambiente, adecuado a los estilos de gobierno y las culturas regionales. La referencia general consiste en la noción de la cultura ciudadana, con matices importantes en cada ciudad: la autorregulación en Bogotá, la convivencia pacífica en Medellín, el conocimiento territorial en Cali y la disciplina ciudadana en Barranquilla. De esta manera, la gestión ambiental constituye parte de un proyecto de gobernabilidad, reforzado por la construcción discursiva de cualidades asociadas al ambiente: calidad de vida, calidad del espacio urbano, seguridad, solidaridad, salud, diver- 
sión, equidad, etc. La clave del éxito de la construcción del bienestar ambiental urbano es su separación radical de la esfera económica y de las funciones tradicionales del Estado benefactor. El bienestar ambiental excluye cualquier consideración de ingresos, empleo y servicios sociales (la distribución social de la riqueza material y cultural) para depositar el bienestar en el medio 'natural': el territorio geográfico y las intervenciones sobre él.

Identidad: Cuando las empresas locales se privatizan (Barranquilla), dirigen su mirada hacia los mercados externos (Grupo Empresarial Antioqueño, Medellín), abandonan su compromiso histórico con la región (Cali), o pasan al control de corporaciones transnacionales (Bogotá), se rompe así un lazo fundamental de identidad local construida alrededor de las economías regionales. La estrategia económica de competitividad es esencialmente exportadora, donde el 'cliente' es el extranjero, sea comprador o inversionista, y la participación de la población local (como accionista, empleado, trabajador) disminuye. Frente a esto, intenta fortalecerse la identidad local a través del ambiente, es decir, las características naturales del territorio como patrimonio propio e inalienable. En Barranquilla se propone una reidentificación con el río Magdalena, otrora fuente de dinamismo urbano y cosmopolitismo; en Cali se urge a conocer los ríos y humedales, montañas y parques; en Bogotá, los cerros, las rondas y los humedales renacen como patrimonio olvidado y maltratado; en Medellín ya existía un fuerte sentido geográfico-cultural en "la capital de la montaña".

Espacialidad: Mientras que la espacialidad de la competitividad fragmenta la ciudad, segrega los grupos sociales y genera enclaves privados, la espacialidad ambiental la articula y produce espacio público. Por un lado, la espacialidad ambiental privilegia el espacio público y el comportamiento ciudadano en relación con él; por otro, resalta los elementos naturales (y la identidad que éstos proporcionan) que generalmente son espacios de flujos y de propiedad o acceso públicos. Ríos, rondas y cerros rodean y deambulan por las ciudades, en una especie de abrazo colectivo que extiende sus manos sin distingo entre barrios ricos y pobres. En Bogotá, este 'sistema ecológico' constituye la base del proyecto del espacio público, que conectará norte y sur, oriente y occidente mediante parques lineales y alamedas. En Barranquilla se plantea la idea de redescubrir la ciudad mediante el rompimiento de la barrera actual que la separa del río Magdalena. En Medellín, las quebradas forman el eje del pro- 
grama de mejoramiento barrial, y el río principal se ha convertido en el lugar del deporte recreativo y fiestas populares. En Cali empieza a entenderse el potencial de rondas y humedales, luego de haberse explotado, hace muchos años y con gran acierto urbanístico, el río Cali en su paso por el centro de la ciudad.

Regulación social: La estrategia económica de competitividad está acompañada por una creciente desregulación de la producción e informalización del trabajo, de tal manera que la economía deja de cumplir la función de esfera de regulación social. La mayoría de las poblaciones urbanas se defiende fuera del sistema formal que antes no sólo determinaba las condiciones laborales sino que también imponía un sistema de valores y comportamientos a los empleados y trabajadores en la conducta integral de sus vidas. La flexibilización e informalización del trabajo y las altas tasas de desempleo en el mundo laboral actual debilitan esta capacidad de establecer y hacer cumplir normas de comportamiento, no sólo aquellas impuestas por las autoridades (empresariales y públicas) sino también las que rigen las relaciones entre los ciudadanos mismos. Las condiciones, los horarios, los lugares, los mecanismos disciplinarios, los códigos éticos y los intereses se fraccionan en el mundo actual de privatización de la responsabilidad por la supervivencia.

Entre los nuevos mecanismos de regulación social (los medios de comunicación son fundamentales), el ambiente juega un papel de creciente importancia. Como vimos arriba, en el ambiente se ha construido un conjunto de valores y principios éticos provenientes de la condición biológica del ser humano y su responsabilidad con la naturaleza entendida como recursos y ecosistemas. Sin embargo, el asunto va más allá de planteamientos abstractos y conocimientos específicos inculcados por la educación ambiental. En la medida que se consolida el sistema nacional ambiental, está tejiéndose una telaraña de instituciones, leyes, normas, procedimientos y sanciones que inciden en la vida individual y social y se entrelazan con los códigos de policía, tránsito, civil y hasta penal. Esta transición del ambiente como código de valores simbólicos a un sistema reglamentario con fuerza de sanciones (componendas, multas, retenciones y detenciones) es más evidente en Bogotá, donde forma parte de un creciente autoritarismo en la vida urbana. En Barranquilla se celebra el paso más modesto en el sentido de establecer límites al comportamiento 'egoísta' del ciudadano, y en Medellín, la posibilidad de establecer relaciones menos violentas entre los ciudadanos. 


\section{Bibliografía}

Acselrad, Henri (1999), "Sustentabilidad y ciudad”, Eure, 25 (74): 35-46.

Barranquilla, Alcaldía (2001), Plan de desarrollo del Distrito de Barranquilla 2001-2003, Barranquilla.

(2000), Plan de ordenamiento territorial del Distrito de Barranquilla, 2 tomos, Barranquilla.

Bogotá, Alcaldía Mayor (1995), Formar ciudad, Plan de Desarrollo Económico y Social 1995-1997, Bogotá.

(1998), Por la Bogotá que queremos, Plan de Desarrollo 1998-2000, Bogotá.

Bogotá, DAMA (2001), Plan de gestión ambiental distrital 20012010, Bogotá.

Brand, Peter (2001), "La construcción ambiental del bienestar urbano: caso de Medellín, Colombia”, Economía, Sociedad y Territorio, El Colegio Mexiquense, A.C., México, III (9): 1-24.

(2005), Urban Environmentalism: Global Change and the Mediation of Local Conflict, Routledge, Londres.

Brenner, Neil y Nik Theodore (2002), Spaces of Neoliberalism, Blackwell, Oxford.

Cali, Alcaldía (2001), Plan de desarrollo de Santiago de Cali 20012003, Cali.

(1998), Plan de desarrollo de Santiago de Cali 1998-2001, Cali.

Cali, Dagma (1999), Diagnóstico: cuidados intensivos (programa de educación ambiental), Cali.

(2001), Silvicultura urbana: acciones de la gente decente para volver a creer, Cali. 
Darrier, Eric (ed.) (1999), Discourses of the Environment, Blackwell, Oxford.

El Heraldo (2001), "Impera la cultura del bochinche", 24 agosto.

(2003a), "Enamorémonos del Río”, sección Ecología, 25 agosto, Barranquilla (versión electrónica: http://www. elheraldo.com.co/ecología/actuar/index/ttlm).

(2003b), "Colaboración ciudadana y mano fuerte", 12 de enero, Barranquilla (versión electrónica http://www. elheraldo.com.co/anteriores//03-01-12/locales).

El País (1999), Chilacos (suplemento del DaGMA distribuido por el periódico), 14 de marzo, Cali.

El Tiempo (2003), sección Opinión, 29 de enero.

Fairclough, Norman (1992), Discourse and Social Change, Polity, Cambridge.

Hajer, Maarten (1995), The Politics of Environmental Discourse, Oxford University Press, Oxford.

Harré, Ron, Jens Brockmeier y Peter Mühlhäusler (1999), Greenspeak: A Study of Environmental Discourse, Sage, Londres.

Harvey, David (1996), Justice, Nature and the Geography of Difference, Blackwell, Oxford.

Huxley, Margo (2002), “Governmentality, Gender, Panning”, en Philip Allmendinger y Mark Tewdwr-Jones (eds.), Planning futures: New Directions for Planning Theory, Routledge, Londres.

Jessop, Bob (1999), “La ciudad empresarial: ¿̇reinvención de las localidades, rediseño de la governance económica o reestructuración del capital?”, en Bob Jessop, Alberto Supelano y Jorge Bula (eds.), Crisis del Estado de Bienestar: hacia una nueva teoría del Estado y sus consecuencias so- 
ciales, Siglo del Hombre Editores-Universidad Nacional de Colombia, Bogotá.

Keil, Roger (2002), “'Common-Sense’ Neoliberalism: Progressive Conservative Neoliberalism in Toronto, Canada", en Neil Brenner y Nik Theodore, Spaces of Neoliberalism, Blackwell, Oxford, pp. 230-253.

Lanthier, Isabel y Lawrence, Olivier (1999), "The Construction of Environmental Awareness", en Eric Darier (ed.), Discourses of the Environment, Blackwell, Oxford, pp. 6378.

Medellín, Alcaldía (1993), Plan General de Desarrollo para Medellín, Medellín.

(2001), Medellín competitiva, Plan de Desarrollo 20012003, Medellín.

Medellín, Concejo Municipal (1989), Problemática ambiental del Valle de Aburrá, (memorias), Medellín.

(1993), Plan General de Desarrollo, Medellín.

Middleton, Neil y Philip O'Keefe (2003), Rio plus Ten: Politics, Poverty and the Environment, Pluto, Londres.

Palacio, German (2002), "Neoliberalismo, ambientalismo y política ambiental”, en Darío Restrepo (ed.), La falacia neoliberal, Universidad Nacional de Colombia, Bogotá.

Rydin, Sue (2003), Conflict, Consensus and Rationality in Environmental Planning: An Institutional Discourse Approach, Oxford University Press, Oxford.

Sandercock, Leonie (2003), "Out of the Closet: The Importance of Stories and Story-telling in Planning”, Planning Theory and Practice, 4 (1): 11-28.

Sharp, Liz y Tim Richardson, (2001), "Reflections on Foucauldian Discourse Analysis in Planning and Environmental 
Policy Research", Journal of Environmental Policy and Planning, 3: 193-209.

Uribe, María Victoria (1996), "Bogotá en los noventa, un escenario de intervención", en Fernando Giraldo y Fernando Viviescas (comps.) Pensar la ciudad, Tercer Mundo, Bogotá.

Recibido: 18 de febrero de 2005. Reenviado: 4 de julio de 2005. Aceptado: 13 de julio de 2005.

Peter Charles Brand es geógrafo de la Universidad de Leeds, Inglaterra, con especializaciones en planeación y diseño urbano, y $\mathrm{PhD}$ en diseño urbano de Oxford Brookes University, Inglaterra. Es profesor de la Universidad Nacional de Colombia (sede Medellín) desde 1982, donde actualmente se desempeña como director de la Escuela de Planeación Urbano-Regional, adscrita a la Facultad de Arquitectura. Coordina el grupo de investigación Dinámicas Urbano-Regionales, y sus intereses investigativos giran alrededor de la incidencia de las ideas ambientales en la planeación, administración y construcción de las ciudades. Su trabajo ha sido divulgado en libros y revistas en Inglaterra y América Latina, y entre sus últimas publicaciones destacan los libros Urban Environmentalism: Global Change and the Mediation of Local Conflict (con Michael J. Thomas), Routledge, Londres, 2005; La invención de futuros urbanos (con Fernando Prada), Universidad Nacional de Colombia, Medellín, 2003, y Trayectorias urbanas en la modernización del Estado en Colombia (editor y compilador), Tercer Mundo-Universidad Nacional-Colciencias, Bogotá, 2001. 